\title{
Local Economic Hardship and Its Role in Life Expectancy Trends
}

\author{
John Bound, Arline T. Geronimus, \\ Timothy A. Waidmann, and Javier M. Rodriguez
}

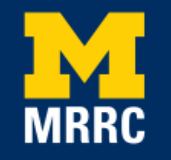

Project \#: R-UM18-07 


\title{
Local Economic Hardship and Its Role in Life Expectancy Trends
}

\author{
John Bound \\ University of Michigan \\ Arline T. Geronimus \\ University of Michigan \\ Timothy A. Waidmann \\ Urban Institute \\ Javier M. Rodriguez \\ Claremount Graduate University \\ October 2018 \\ Michigan Retirement Research Center \\ University of Michigan \\ P.O. Box 1248 \\ Ann Arbor, MI 48104 \\ www.mrrc.isr.umich.edu \\ (734) 615-0422
}

\section{Acknowledgements}

The research reported herein was performed pursuant to a grant from the U.S. Social Security Administration (SSA) funded as part of the Retirement Research Consortium through the University of Michigan Retirement Research Center Award RRC08098401-10. The opinions and conclusions expressed are solely those of the author(s) and do not represent the opinions or policy of SSA or any agency of the federal government. Neither the United States government nor any agency thereof, nor any of their employees, makes any warranty, express or implied, or assumes any legal liability or responsibility for the accuracy, completeness, or usefulness of the contents of this report. Reference herein to any specific commercial product, process or service by trade name, trademark, manufacturer, or otherwise does not necessarily constitute or imply endorsement, recommendation or favoring by the United States government or any agency thereof.

\section{Regents of the University of Michigan}

Michael J. Behm, Grand Blanc; Mark J. Bernstein, Ann Arbor; Shauna Ryder Diggs, Grosse Pointe; Denise Ilitch, Bingham Farms; Andrea Fischer Newman, Ann Arbor; Andrew C. Richner, Grosse Pointe Park; Ron Weiser, Ann Arbor; Katherine E. White, Ann Arbor; Mark S. Schlissel, ex officio 


\title{
Local Economic Hardship and Its Role in Life Expectancy Trends
}

\begin{abstract}
Recent research has found, in some groups of Americans, dramatic increases in deaths due to drug overdose and suicide and an overall stagnation of trends toward increased longevity. This study examines the link between mortality of older working age (45 to 64) adults and local economic downturns in the U.S. to evaluate the role of economic shifts in various causes of death and their related mortality trends. Specifically, we estimate regression models to test the hypotheses that the longevity effects of poor economic prospects are reflected through (1) increased suicide, drug overdose, and other "deaths of despair" and (2) other causes of death linked to exposure to economic and social stress such as heart and cerebrovascular disease. To avoid the problem of endogeneity of local economic conditions to mortality conditions, we measure the local economic shock of lost employment with predicted employment based on baseline industrial composition and national trends in employment by industry. We find evidence consistent with prior research that among non-Hispanic white adults, midlife mortality has increased since 1990, particularly among those with low educational attainment. We also find that "deaths of despair" are important contributors to that trend. However, we find that while distress in local, area economies does predict increased mortality for chronic disease, it predicts decreased mortality from suicides, opioids, and other substance abuse. This finding suggests caution in the application of the construct of despair in explaining recent mortality patterns.
\end{abstract}

\section{Citation}

Bound, John, Arline T. Geronimus, Timothy A. Waidmann, and Javier M. Rodriguez. 2018. "Local Economic Hardship and Its Role in Life Expectancy Trends," Ann Arbor MI: University of Michigan Retirement Research Center (MRRC) Working Paper, WP 2018-389. https://mrdrc.isr.umich.edu/publications/papers/pdf/wp389.pdf

\section{Authors' acknowledgements}

The findings and conclusions expressed are solely those of the authors and do not represent the views of the SSA, any agency of the federal government, the University of Michigan, Claremont Graduate University, or the Urban Institute. The authors thank Brenden Timpe for research assistance. 
Over the last decade, several investigators have documented the stagnation or possible decrease in life expectancy among United States residents on the bottom rungs of the socioeconomic ladder. (Bound et al. 2015; Case \& Deaton 2015; Meara et al. 2008; Montez et al. 2011; Olshansky et al. 2012) Recent high profile work (Case \& Deaton 2015, 2017; Chetty et al. 2016) revived a discussion begun several years ago highlighting apparent dramatic declines in life expectancy particularly for whites with low levels of education. Their most recent findings highlight increases in crude death rates among working-aged whites since 2000, a trend that differs by cause of death, sex, and age group from other groups in the U.S. as well as other advanced Western economies (Case \& Deaton 2017). Although their main findings largely focus on a narrow age range for a single demographic group where the changes are most dramatic, the evidence produced suggests that increased mortality among certain whites stems from increases in so-called "deaths of despair" (Monnat 2016), prominently including illegal and prescription drug overdoses, alcoholism, and suicide (Case \& Deaton 2017).

Beyond the public health significance of these findings, newly developed narratives suggest the increasing "despair" that such deaths represent in the working-class, white population may be traceable to the economic stagnation these groups have experienced over the last half century (Autor 2014). Other promising research has found links between local economic downturns and the morbidity and mortality rates associated with "despair" causes (Hollingsworth et al. 2017; Pierce \& Schott 2016). However, there are several potential problems with these narratives. First, death rates from suicide and substance use have not consistently fluctuated with major macroeconomic changes over the last decade — the period in which these deaths are more prominent. For example, while the Great Recession was particularly deep, economic conditions have drastically improved since 2010, but the death rates for these causes have not. Further, while Case and Deaton's work identifies large changes in suicide and substance use in one narrow band of the population (45- to 54-year-old, non-Hispanic whites), 
these trends do not appear to hold among groups in similar or worse economic shape. It is also not a settled matter that economic downturns are unequivocally bad for mortality. Indeed some have found evidence that increases in unemployment reduce some types of mortality (Ruhm 2000; Tapia Granados 2005; Tapia Granados \& Diez Roux 2009). Other research also critiques the framing of these types of death as primarily a result of despair (Columbia University 2018; Geronimus et al. 2017; Muennig et al. 2018).

To reconcile these possible contradictions, Case and Deaton speculate that it is relative distress compared to one's expectations of economic opportunity, rather than absolute levels of economic distress, that lead low-education whites to self-destructive health behavior. Although this narrative draws some of its force from the diverse work cited above describing stagnation in longevity among low-education whites and the growing gap in life expectancy between higher and lower education groups (Bound et al. 2015), the most recent work focuses on changes in cause-specific death rates in specific age groups, not life expectancy. Despite their speculation that increased deaths from suicide and drug use spring from failure to access expected levels of economic opportunity, Case and Deaton did not empirically evaluate their speculation for stagnation in life expectancy. Nor has any investigation, to our knowledge, systematically attempted to do so.

In this paper, we assess the importance of economic stagnation for explaining differential trends in mortality in the older, working-aged population (ages 45 to 64). We do this by comparing mortality trends in geographic locations that experienced the greatest economic downturn related to the changing industrial composition of employment to trends in locations that have either benefited or experienced less of a downturn. We expand on our earlier work (Geronimus et al. 2017) by systematically exploring the link between economic hardship and mortality trends among groups with low socioeconomic position. 
We focus our attention on this age group, as have many others in recent literature, for several reasons. First, this age group is historically important as a source of income for families and productivity for the economy as a whole. Second, the recent slowing and reversal of gains in life expectancy can be accounted for primarily by changes in death rates before age 65 . Third, deaths before age 65 have a greater mathematical impact on life expectancy than those at later ages, since they cost more in terms of years lost.

In particular, we are interested in whether recently observed stagnation in longevity among low-education groups is geographically coincident with local economic downturns. We also examine the hypothesis that worsening economic prospects are associated specifically with trends in mortality related to suicide and substance use as well as stress-related chronic diseases. This comparison is particularly useful when considering that the latter have been found to have early onset among disadvantaged populations suffering cumulative exposure to chronic stress over the reproductive and working ages (Geronimus et al. 2011). A first approximation to disentangle mortality rates for so-called "deaths of despair" from stress-related chronic diseases would be to use a simple measure of local economic hardship related to industrial change, such as the change in local employment rates. However, because employment may be endogenous to changes in local demographic factors (including changes imparted by mortality), we instead use a more plausibly exogenous measure of employment change — known as a shift-share or Bartik instrument (Bartik 1991; Bound \& Holzer 2000). This measure replaces actual, local employment change with a local change predicted by local industrial composition at baseline and national employment change by industry. 


\section{Data and Methods}

Data come from three principal sources. For mortality we use data from the 1990 to 2015 Multiple Cause of Death files, which contain individual-level information on decedents in the United States, including cause(s) of death, age, sex, race, ethnicity, and educational attainment, supplemented with the geocode data identifying county of residence. To estimate the population at risk of death using the same covariates, we used bridged-race estimates for U.S. residents, which conform U.S. Census population estimates to vital statistics race/ethnicity categories. We will focus on individuals between the ages of 25 and 84, rather than older ages because data tend to be more reliable for this age range. To control for differences in age composition between populations by race, sex, year, and educational attainment, we measure changes in mortality conditions using age-standardized death rates (ASDR). To construct the shift-share instrument of employment change, we used the 1980 decennial census to set the baseline distribution of industrial composition in aggregate and by education (high school or less versus some college or more). National growth in employment by industry, in aggregate and by education, was calculated using the 1980 decennial census and the five-year (2012 to 2016) pooled sample of the American Community Survey (ACS).

While many existing studies of local economic conditions use county as the unit of analysis, establishing a convincing link between local mortality and its economy requires that there is minimal relocation of populations (Currie \& Schwandt 2016; Geronimus et al. 2014). For this reason county may be too small an area to use as a unit of analysis, and others have found very little migration in or out of larger units, including metropolitan statistical areas (Bound \& Holzer 2000) and commuting zones (CZ) as defined by the U.S. Department of Agriculture (Autor et al. 2013; "USDA ERS - Documentation," n.d.). Thus, to mitigate the problems caused by mobility within a labor market and increase the reliability of local area estimates, data from all sources were aggregated to the $\mathrm{CZ}$ level. 
To measure the importance of lost economic opportunity on overall deaths, deaths from suicide and substance use, sometimes referred to as "deaths of despair" (DoD), and deaths due to stress-related chronic disease, we estimated reduced form regressions of changes in ASDRs on the shift-share instrument of employment change at the $\mathrm{CZ}$ level, by sex, race (non-Hispanic whites and non-Hispanic blacks), and education $(<=\mathrm{HS},>\mathrm{HS})$. The ASDRs were calculated for two age ranges ( 45 to 64 and 45 to 54 ), both for all causes in aggregate and separately by cause (DoD, cancer, CVD, other internal causes, and other external causes).

The Bartik index for commuting zone $c$ and education group $e$, is defined as the national level change in $(\log )$ shares of employment by industry $i$ between 1980 and 2014 weighted by the commuting zone share of employment by industry in 1980 , or

$$
B_{c e}=\sum_{i} \frac{e m p 80_{i c e}}{e m p 80_{c e}}\left[\ln \left(\frac{e m p 14_{i e}}{e m p 14_{e}}\right)-\ln \left(\frac{e m p 80_{i e}}{e m p 80_{e}}\right)\right]
$$

In general, the more a local area economy was susceptible to broad economic changes of the last three decades, the more negative the index. Thus, we estimate regressions of the form

$$
\Delta A S D R_{\text {cersaj }}=\alpha_{r s a j}+\beta_{r s a j} B_{c e}+\epsilon
$$

where $r$ indexes race, $s$ indexes sex, $a$ indexes age group, and $j$ indexes cause of death. Observations are weighted by population size in each group, and standard errors are estimated robust to heteroskedasticity. Since positive values of the Bartik instrument indicate improving employment prospects and negative values indicate declining prospects, if economic distress drives up all-cause or any cause-specific death rates, we expect the coefficients in these regressions to be negative. 


\section{Results}

Changes in age-standardized death rates, 1990 to 2014

Tables 1 and 2 show the changes in ASDR between 1990 and 2014 by race, sex, education, and cause of death for two age ranges, 45 to 64 and 45 to 54 . The ages between 45 and 64 are when most deaths among nonelderly adults occur, but this is still an age range where death is considered to be premature by current standards in the developed world. The 45 to 54 range was chosen in part so that we can compare our findings with those gaining attention in recent academic and media coverage (Case \& Deaton 2015). These changes are calculated as weighted averages across commuting zone areas.

Among non-Hispanic whites 45 to 64 (Table 1), men experienced no significant change in all-cause mortality between 1990 and 2014, either as a single group, or divided by educational attainment. While non-Hispanic, white women as a whole did not have a statistically significant change in all-cause mortality, when we divided them by educational attainment, both educational groups $(<=\mathrm{HS},>\mathrm{HS})$ had statistically significant increases over this period. ${ }^{1}$ All-cause mortality increased by $31.44(\mathrm{P}<.05)$ deaths per 100,000 women with some education beyond high school and by $103.94(\mathrm{P}<.01)$ deaths per 100,000 women with high school or less.

Examining the changes in cause-specific mortality among non-Hispanic whites ages 25 to 64, we see offsetting changes for both men and women. "Deaths of despair" (i.e., deaths due to opioids and other drugs, alcohol poisoning, and suicide) increased significantly for both men and women in both higher and lower education groups, as well as when undifferentiated by education. Conversely, deaths due to cancer and cardiovascular disease (CVD) fell significantly,

\footnotetext{
${ }^{1}$ This apparent anomaly is a result of changing educational attainment between 1990 and 2014. While both education specific rates were falling, the composition of the population was shifting toward higher educational attainment over this period.(Bound et al. 2015). Since death rates among the high education group were lower, this compositional shift puts downward pressure on the overall death rate, counteracting the changes within education groups.
} 
both overall and when rates were examined separately by education (except for CVD among high-education, white women, where the decline was not significant). Deaths due to other diseases ("other internal") increased significantly, by magnitudes similar to or even greater than those for deaths of despair.

We see a different pattern of mortality changes among non-Hispanic blacks in this age range. In particular, when we do not differentiate by educational attainment, non-Hispanic, black men had a large and statistically significant decrease in all-cause death rates between 1990 and 2014, and non-Hispanic, black women had no significant change. Both men and women had small but statistically significant increases in deaths of despair, while men had significant decreases deaths in cancer and CVD. Among black men, these declines are strongest among those with lower educational attainment. Among black women, declines in CVD death rates were statistically significant for the whole group and for those with low education. Death rates for other internal causes, however, were increasing.

Table 2 focuses more narrowly on the age range highlighted in a prominent recent analysis, those ages 45 to 54 . For the most part, the findings are similar, though there are a few differences. Notably, among non-Hispanic, white men, the all-cause mortality rates increased significantly. The largest contributor to these increases was increased deaths of despair, which were offset by significant decreases in cancer and CVD deaths. Similar patterns are found for white women, with significant increases in all-cause mortality in every education group and increases in deaths of despair, but the offset caused by declines in cancer and CVD are less sizeable. For both men and women, the increases in all-cause and despair death rates were most pronounced among the low education group.

Among non-Hispanic, black men ages 45 to 54 , the all-cause mortality rate fell significantly for the whole group and for those with a high school education or less. These changes were accounted for mostly by declines in cancer and CVD deaths. Among non-Hispanic, 
black women ages 45 to 54, all-cause mortality rates did not change significantly, but rates for DoD and other internal causes did increase.

\section{The role of economic distress in changing mortality rates}

We then estimated the relationship between local area mortality changes and the index of the local economy's vulnerability to national industrial shifts defined in equation (1). As shown in Table 3, we find limited evidence that economic distress predicts changes in mortality rates for non-Hispanic whites ages 45 to 64 , but these effects may be concentrated among those with lower levels of education. For all-cause mortality, the only statistically significant estimate is for low-education white women $(\mathrm{P}<0.05)$. This finding seems to be driven mostly by statistically significant economic effects on cancer deaths and other internal causes. Perhaps surprisingly,given the framing of suicide and drug overdose as a symptom of economic despair, DoD death rates in each low-education group increase significantly with better economic conditions. For non-Hispanic, black men and women, these effects are also positive and significant when we do not differentiate by education.

Findings for just the 45- to 54-year-old group (Table 4) tell a similar story for nonHispanic white men and women, with economic distress predicting increases in all-cause, cancer, and other internal mortality. We also find these statistically significant effects for low-education women in cancer and other external causes of death. Unlike the findings for 45 to 64 year olds, no statistically significant relationships are detected between economic distress and DoD mortality. The one group for whom we still find a relationship is among black men, particularly those with lower levels of education. For these men, economic distress is associated with lower levels of DoD mortality. 


\section{Importance of economic factors relative to actual mortality changes}

While the preceding analyses show some statistically significant relationships between economic conditions and mortality rates, they do not provide a clear estimate of the importance of economic factors in explaining mortality change relative to other factors. To make this assessment, for each commuting zone (CZ), we calculated the changes in all-cause and causespecific death rates. In Figures 1 and 2, we present examples of these calculations for nonHispanic, white men and women with no more than a high school education - the two population groups with the strongest statistical relationships between death rates and economic conditions.

Figure 1 shows results for low-education, white men. Between 1990 and 2014, the agestandardized, all-cause death rate for this group increased by 43.84 deaths per 100,000 while the average change predicted by local economic conditions was 39.03 . While this suggests that economic conditions are highly predictive for all-cause mortality, the cause-specific results show otherwise. The DoD death rate was predicted to fall by 9.96 on average, while the actual death rate increased by 81.77 . Cancer deaths were predicted to increase by 27.22 but actually fell by 46.12. While the coefficient was not significantly different from zero, cardiovascular deaths were predicted to fall by 0.76 while the actual rate fell by 112.45 . Other internal deaths were predicted to increase by 22.09 while the actual rate increased by 105.33 . Figure 2 shows qualitatively similar comparisons for low education white women.

\section{Discussion}

The findings presented in this paper (Tables $1 \& 2$ ) are consistent with other research showing a recent increase in mortality for older, working-aged, non-Hispanic, white women, and that these increases are most prominent among the subset of this group with low educational attainment. Our findings are also consistent with those which highlight the centrality of suicide, drug overdose deaths, and alcohol poisoning for this group's mortality increases in particular, as 
well as demonstrating that these types of death are increasing in many segments of the population. These types of deaths are also increasing among older, middle-aged, non-Hispanic blacks, but in that group, suicide and substance use deaths are moving in the opposite direction of chronic disease deaths, which are on the decline, often dramatically so. Finally, we also find that the midlife mortality gap between more educated and less educated whites is growing, not only as a result of deaths of despair, but also because of differential death rates in stress-related chronic disease.

When we examine the correlation between distressed local economies and mortality trends (Tables $3 \& 4$ ), we find first that even pooling over five years of mortality data, the imprecision of our estimates for non-Hispanic blacks is often too large to draw conclusions about the relationship. Among non-Hispanic whites, however, we find that local areas where the economy was reliant on industries in decline nationally had greater increases in mortality than areas with less such economic vulnerability. This was especially true for populations with no more than a high school education - a group more likely to be employed in blue collar jobs. Examining death rates for separate causes of death, this pattern also holds for deaths due to stress-related chronic diseases and cancer, a finding consistent with the weathering hypothesis that prolonged exposure to stress increases allostatic load leading to higher rates of cancer and certain cardiovascular diseases. Strikingly, however, this pattern did not hold for deaths due to suicide and substance use, where we find the opposite. That is, when a relationship was found to be statistically significant, DoD increased more in areas with less economic vulnerability than in areas with more vulnerability. This finding, in particular, calls into question the hypothesis behind the term "deaths of despair." If the increase in these deaths were a result of economic despair, we would expect that areas hardest hit by industrial change would see the greatest mortality increase. This finding is consistent with other recent research using different methods (Ruhm 2018). 
For each of the causes studied, however, the economic changes we measure are not sufficient to explain observed changes in death rates. In particular, economic vulnerability alone would have predicted increases in deaths due to both cancer and cardiovascular diseases between 1990 and 2014, while these death rates fell. Thus other factors (e.g., declines in smoking) may have been more important than economic stress in determining the overall change in these rates. In the case of suicides and deaths due to substance use, something other than economic despair must be at work. With these data we can't tell whether this other factor is geographic variation in the supply of or demand for opioids and other drugs, prescribing behavior of physicians, availability of firearms, or something else entirely.

Further work is needed to bring in data on other potential explanations for changing death rates and to find ways to reduce variability in regression estimates, especially if we are to understand the sources of mortality change among non-Hispanic blacks. It is also the case that the particular measure of economic distress we use is a single, and perhaps imperfect, summary of economic conditions. Other indicators may represent other, more specific aspects of economic conditions (e.g., susceptibility of a local economy to automation or foreign trade, differences in the safety of prevalent jobs). Adding these other indicators may either fill in missing parts of the story or tell a different story entirely.

There are several policy implications of this research. First, even as average life expectancy in the U.S. has risen overall during the past decades, for those in the bottom of the socioeconomic distribution, it has stagnated or even fallen since 1990. These trends suggest that an increasing fraction of adults do not reach normal retirement age. Understanding whether these changes reflect the business cycle or represent a longer-term impact of structural changes to the economy has important implications for Social Security policy. Our findings suggest that structural conditions of local economies have implications for longevity that may affect both the revenue collected and benefits paid by Social Security. Policies intended to increase longevity 
generally, or to decrease disparities between higher and lower SES groups, need to recognize the complex relationship between economic conditions and mortality, but they may also need to search beyond economic stability if they are to turn the increasing rates of death from substance abuse and suicide. 


\section{References}

Autor, D. H. (2014). Skills, education, and the rise of earnings inequality among the "other 99 percent." Science, 344(6186), 843-851. https://doi.org/10.1126/science.1251868

Autor, D. H., Dorn, D., \& Hanson, G. H. (2013). The China Syndrome: Local Labor Market Effects of Import Competition in the United States. American Economic Review, 103(6), 2121-2168. https://doi.org/10.1257/aer.103.6.2121

Bartik, T. J. (1991). Who Benefits from State and Local Economic Development Policies? W.E. Upjohn Institute. https://doi.org/10.17848/9780585223940

Bound, J., Geronimus, A. T., Rodriguez, J. M., \& Waidmann, T. A. (2015). Measuring Recent Apparent Declines In Longevity: The Role Of Increasing Educational Attainment. Health Affairs, 34(12), 2167-2173. https://doi.org/10.1377/hlthaff.2015.0481

Bound, J., \& Holzer, H. J. (2000). Demand Shifts, Population Adjustments, and Labor Market Outcomes during the 1980s. Journal of Labor Economics, 18(1), 20-54. https://doi.org/10.1086/209949

Case, A., \& Deaton, A. (2015). Rising morbidity and mortality in midlife among white nonHispanic Americans in the 21st century. Proceedings of the National Academy of Sciences of the United States of America, 112(49), 15078-15083. https://doi.org/10.1073/pnas.1518393112

Case, A., \& Deaton, A. (2017). Mortality and morbidity in the 21st century (Brookings Papers on Economic Activity). Brookings Institution.

Chetty, R., Stepner, M., Abraham, S., Lin, S., Scuderi, B., Turner, N., .. Cutler, D. (2016). The Association Between Income and Life Expectancy in the United States, 2001-2014. JAMA. https://doi.org/10.1001/jama.2016.4226 
Columbia University. (2018, September 27). Deaths of despair: The opioid epidemic is just part of the problem: Rising medical costs may be the biggest contributor to declines in lifeexpectancy. Retrieved October 1, 2018, from https://www.sciencedaily.com/releases/2018/09/180927164235.htm

Currie, J., \& Schwandt, H. (2016). Mortality Inequality: The Good News from a County-Level Approach. Journal of Economic Perspectives, 30(2), 29-52. https://doi.org/10.1257/jep.30.2.29

Geronimus, A. T., Bound, J., \& Colen, C. G. (2011). Excess black mortality in the United States and in selected black and white high-poverty areas, 1980-2000. American Journal of Public Health, 101(4), 720-729. https://doi.org/10.2105/AJPH.2010.195537

Geronimus, A. T., Bound, J., \& Ro, A. (2014). Residential Mobility Across Local Areas in the United States and the Geographic Distribution of the Healthy Population. Demography, 51(3), 777-809. https://doi.org/10.1007/s13524-014-0299-4

Geronimus, A. T., Bound, J., Waidmann, T. A., Rodriguez, J. M., \& Timpe, B. (2017). Causes of Widening Educational Inequity in U.S. Life Expectancy by Sex and Race, 1990-2015. University of Michigan.

Hollingsworth, A., Ruhm, C. J., \& Simon, K. (2017). Macroeconomic conditions and opioid abuse. Journal of Health Economics, 56, 222-233. https://doi.org/10.1016/j.jhealeco.2017.07.009

Meara, E. R., Richards, S., \& Cutler, D. M. (2008). The Gap Gets Bigger: Changes In Mortality And Life Expectancy, By Education, 1981-2000. Health Affairs, 27(2), 350-360. https://doi.org/10.1377/hlthaff.27.2.350 
Monnat, S. M. (2016). Deaths of despair and support for Trump in the 2016 presidential election. The Pennsylvania State University Department of Agricultural Economics, Sociology, and Education. Retrieved from http://aese.psu.edu/directory/smm67/Election16.pdf

Montez, J. K., Hummer, R. A., Hayward, M. D., Woo, H., \& Rogers, R. G. (2011). Trends in the Educational Gradient of U.S. Adult Mortality from 1986 to 2006 by Race, Gender, and Age Group. Research on Aging, 33(2), 145-171. https://doi.org/10.1177/0164027510392388

Muennig, P. A., Reynolds, M., Fink, D. S., Zafari, Z., \& Geronimus, A. T. (2018). America’s Declining Well-Being, Health, and Life Expectancy: Not Just a White Problem. American Journal of Public Health, e1-e6. https://doi.org/10.2105/AJPH.2018.304585

Olshansky, S. J., Antonucci, T., Berkman, L., Binstock, R. H., Boersch-Supan, A., Cacioppo, J. T., ... Goldman, D. P. (2012). Differences in life expectancy due to race and educational differences are widening, and many may not catch up. Health Affairs, 31(8), 1803-1813.

Pierce, J. R., \& Schott, P. K. (2016). Trade Liberalization and Mortality: Evidence from U.S. Counties (No. w22849). Cambridge, MA: National Bureau of Economic Research. https://doi.org/10.3386/w22849

Ruhm, C. J. (2000). Are Recessions Good for Your Health? The Quarterly Journal of Economics, $115(2), 617-650$.

Ruhm, C. J. (2018). Deaths of Despair or Drug Problems? (Working Paper No. 24188). National Bureau of Economic Research. https://doi.org/10.3386/w24188

Tapia Granados, J. A. (2005). Increasing mortality during the expansions of the US economy, 1900-1996. International Journal of Epidemiology, 34(6), 1194-1202. https://doi.org/10.1093/ije/dyi141 
Tapia Granados, J. A., \& Diez Roux, A. V. (2009). Life and death during the Great Depression. Proceedings of the National Academy of Sciences of the United States of America, 106(41), 17290-17295. https://doi.org/10.1073/pnas.0904491106

USDA ERS - Documentation. (n.d.). Retrieved September 11, 2018, from https://www.ers.usda.gov/data-products/commuting-zones-and-labor-marketareas/documentation/ 
Table 1. Change in age-standardized death rates (per 100,000), 1990 to 2014, by sex, race, and education, ages 45 to 64

non-Hispanic Whites

non-Hispanic Blacks

\begin{tabular}{|c|c|c|c|c|c|c|c|c|c|c|c|c|}
\hline & \multicolumn{12}{|c|}{ Men } \\
\hline Cause of Death & All Education & & >High Sch & & $<=$ High Sch & & All Education & & >High Sch & & $<=$ High Sch & \\
\hline All Causes & -45.25 & & -18.39 & & 43.84 & & -284.32 & $*$ & -98.60 & & -227.20 & \\
\hline std. error & 34.50 & & 27.30 & & 41.01 & & 125.82 & & 84.79 & & 138.84 & \\
\hline DoD & 55.35 & $* *$ & 37.67 & $* *$ & 81.77 & $* *$ & 14.44 & $*$ & 15.43 & $* *$ & 24.45 & $* *$ \\
\hline se & 2.01 & & 1.69 & & 2.59 & & 6.00 & & 3.94 & & 7.12 & \\
\hline Cancer & -55.92 & $* *$ & -31.83 & $* *$ & -46.12 & $* *$ & -138.83 & $* *$ & -68.14 & $*$ & -133.21 & $* *$ \\
\hline se & 12.15 & & 9.68 & & 14.34 & & 39.29 & & 27.69 & & 43.14 & \\
\hline CVD & -104.17 & $* *$ & -57.35 & $* *$ & -112.45 & $* *$ & -150.41 & $* *$ & -62.59 & & -148.21 & $* *$ \\
\hline se & 13.40 & & 9.95 & & 16.56 & & 48.72 & & 34.36 & & 53.97 & \\
\hline Other Internal & 50.13 & $* *$ & 25.48 & $* *$ & 105.53 & $* *$ & 6.29 & & 15.68 & & 42.68 & \\
\hline se & 7.30 & & 6.45 & & 7.86 & & 28.01 & & 19.51 & & 30.89 & \\
\hline Other External & 9.33 & $* *$ & 7.58 & $* *$ & 15.10 & $* *$ & -16.13 & $*$ & -.63 & & -12.94 & \\
\hline \multirow[t]{2}{*}{ se } & 1.41 & & 1.19 & & 1.75 & & 6.82 & & 4.24 & & 7.93 & \\
\hline & \multicolumn{12}{|c|}{ Women } \\
\hline Cause of Death & All Education & & $>$ High Sch & & $<=$ High Sch & & All Education & & $>$ High Sch & & $<=$ High Sch & \\
\hline All Causes & 13.76 & & 31.44 & $*$ & 103.94 & $* *$ & -44.80 & & 20.09 & & 15.95 & \\
\hline std. error & 20.85 & & 15.96 & & 23.49 & & 70.44 & & 55.29 & & 74.09 & \\
\hline DoD & 32.17 & $* *$ & 22.94 & $* *$ & 47.80 & $* *$ & 12.74 & $* *$ & 10.31 & $* *$ & 19.93 & $* *$ \\
\hline se & 1.17 & & 1.11 & & 1.31 & & 1.80 & & 1.42 & & 2.31 & \\
\hline Cancer & -39.95 & $* *$ & -21.05 & $*$ & -28.56 & $*$ & -18.68 & & -13.70 & & -9.93 & \\
\hline se & 10.42 & & 8.92 & & 11.47 & & 25.46 & & 25.27 & & 25.32 & \\
\hline CVD & -29.60 & $* *$ & -6.64 & & -18.18 & $* *$ & -81.49 & $* *$ & -25.00 & & -70.43 & $*$ \\
\hline se & 5.45 & & 3.51 & & 6.70 & & 27.24 & & 18.52 & & 29.73 & \\
\hline Other Internal & 47.56 & $* *$ & 33.35 & $* *$ & 96.10 & $* *$ & 43.52 & $* *$ & 51.85 & $* *$ & 75.35 & $* *$ \\
\hline se & 4.74 & & 3.29 & & 5.47 & & 16.21 & & 10.72 & & 18.03 & \\
\hline Other External & 3.54 & $* *$ & 2.73 & $* *$ & 6.78 & $* *$ & -1.04 & & -4.01 & & 1.01 & \\
\hline se & .55 & & .50 & & .63 & & 1.58 & & 3.06 & & 1.75 & \\
\hline
\end{tabular}

Source: Authors' tabulations using 1990 to 2014 National Vital Statistics, U.S. decennial census, and American Community Survey.

Notes: ${ }^{*} \mathrm{P}<0.01 ; * \mathrm{P}<0.05 ; \mathrm{DoD}=$ Deaths of Despair; $\mathrm{CVD}=$ Cardiovascular disease; $\mathrm{se}=($ robust $)$ standard error 
Table 2. Change in age standardized death rates (per 100,000), 1990 to 2014, by sex, race, and education, Ages 45 to 54

\begin{tabular}{|c|c|c|c|c|c|c|c|c|c|c|c|c|}
\hline \multirow[b]{3}{*}{ Cause of Death } & \multicolumn{5}{|c|}{ non-Hispanic Whites } & \multicolumn{7}{|c|}{ non-Hispanic Blacks } \\
\hline & \multicolumn{12}{|c|}{ Men } \\
\hline & All Education & & >High Sch & & $<=$ High Sch & & All Education & & >High Sch & & $<=$ High Sch & \\
\hline All Causes & 46.89 & $*$ & 20.52 & & 98.52 & $* *$ & -227.64 & $* *$ & -41.60 & & -245.93 & $*$ \\
\hline std. error & 19.71 & & 15.88 & & 25.01 & & 87.93 & & 48.76 & & 106.49 & \\
\hline DoD & 64.13 & $* *$ & 39.86 & $* *$ & 94.96 & $* *$ & 3.75 & & 10.01 & $* *$ & 8.51 & \\
\hline se & 2.25 & & 1.70 & & 3.16 & & 6.54 & & 3.29 & & 8.60 & \\
\hline Cancer & -21.99 & $* *$ & -12.05 & $* *$ & -27.89 & $* *$ & -96.55 & $* *$ & -31.48 & $*$ & -115.01 & $* *$ \\
\hline se & 5.65 & & 4.35 & & 7.48 & & 23.06 & & 13.58 & & 27.89 & \\
\hline CVD & -31.78 & $* *$ & -15.29 & $* *$ & -43.87 & $* *$ & -82.11 & $* *$ & 1.20 & & -99.59 & $* *$ \\
\hline se & 6.49 & & 4.61 & & 9.03 & & 30.34 & & 15.29 & & 37.94 & \\
\hline Other Internal & 27.80 & $* *$ & 2.07 & & 62.08 & $* *$ & -37.08 & & -19.98 & & -25.78 & \\
\hline se & 5.98 & & 5.90 & & 6.00 & & 24.87 & & 16.64 & & 29.12 & \\
\hline Other External & 8.70 & $* *$ & 5.86 & $* *$ & 13.23 & $* *$ & -15.73 & $*$ & -1.55 & & -14.08 & \\
\hline \multirow[t]{2}{*}{ se } & 1.40 & & 1.13 & & 1.96 & & 6.90 & & 4.28 & & 8.36 & \\
\hline & \multicolumn{12}{|c|}{ Women } \\
\hline Cause of Death & All Education & & $>$ High Sch & & $<=$ High Sch & & All Education & & $>$ High Sch & & $<=$ High Sch & \\
\hline All Causes & 59.40 & $* *$ & 45.37 & $* *$ & 142.53 & $* *$ & 4.28 & & 59.08 & & 53.32 & \\
\hline std. error & 11.79 & & 8.96 & & 14.12 & & 45.13 & & 30.16 & & 51.20 & \\
\hline DoD & 39.74 & $* *$ & 26.58 & $* *$ & 62.39 & $* *$ & 13.41 & $* *$ & 11.84 & $* *$ & 21.23 & $* *$ \\
\hline se & 1.40 & & 1.26 & & 1.73 & & 2.02 & & 1.75 & & 2.76 & \\
\hline Cancer & -22.61 & $* *$ & -9.58 & & -18.54 & $*$ & -14.48 & & .76 & & -11.13 & \\
\hline se & 6.14 & & 5.02 & & 7.38 & & 16.93 & & 15.03 & & 18.03 & \\
\hline CVD & 2.30 & & 5.01 & $* *$ & 15.88 & $* *$ & -25.15 & & 7.25 & & -17.43 & \\
\hline se & 2.46 & & 1.62 & & 3.37 & & 15.54 & & 9.27 & & 18.48 & \\
\hline Other Internal & 36.26 & $* *$ & 20.80 & $* *$ & 75.13 & $* *$ & 30.78 & $* *$ & 37.38 & $* *$ & 58.96 & $* *$ \\
\hline se & 2.78 & & 1.93 & & 3.44 & & 11.19 & & 6.55 & & 13.74 & \\
\hline Other External & 3.68 & $* *$ & 2.46 & $* *$ & 7.67 & $* *$ & -.32 & & 1.70 & & 1.71 & \\
\hline se & .58 & & .52 & & .72 & & 1.53 & & 1.46 & & 1.93 & \\
\hline
\end{tabular}

Source: Authors' tabulations using 1990 to 2014 National Vital Statistics, U.S. decennial census, and American Community Survey.

Notes: $* * \mathrm{P}<0.01 ; * \mathrm{P}<0.05 ; \mathrm{DoD}=$ Deaths of Despair; $\mathrm{CVD}=$ Cardiovascular disease; $\mathrm{se}=($ robust $)$ standard error 
Table 3. Coefficient estimates in regressions of ASDR change on shift-share employment instrument, ages 45 to 64

non-Hispanic Whites

non-Hispanic Blacks

\begin{tabular}{|c|c|c|c|c|c|c|c|c|c|c|c|c|}
\hline \multirow[b]{2}{*}{ Cause of Death } & \multicolumn{12}{|c|}{ Men } \\
\hline & All Education & & >High Sch & & $<=$ High Sch & & All Education & & >High Sch & & $<=$ High Sch & \\
\hline All Causes & -130.45 & & -304.32 & & -219.62 & & 370.99 & & 2223.89 & & 76.17 & \\
\hline std. error & 233.49 & & 554.35 & & 208.40 & & 791.27 & & 1762.63 & & 588.46 & \\
\hline DoD & 11.64 & & -3.09 & & 56.03 & $* *$ & 91.70 & $*$ & 88.52 & & 96.56 & $* *$ \\
\hline se & 14.57 & & 25.28 & & 16.35 & & 40.73 & & 79.69 & & 36.08 & \\
\hline Cancer & -66.69 & & -60.19 & & -153.19 & $*$ & 5.01 & & 521.22 & & -103.83 & \\
\hline se & 82.59 & & 206.28 & & 70.68 & & 244.26 & & 578.93 & & 178.68 & \\
\hline CVD & 89.15 & & 54.39 & & 4.27 & & 317.00 & & 1352.65 & $*$ & 160.30 & \\
\hline se & 91.58 & & 207.22 & & 83.29 & & 298.65 & & 688.05 & & 222.38 & \\
\hline Other Internal & -160.31 & $* *$ & -273.21 & $*$ & -124.28 & $* *$ & -66.31 & & 305.66 & & -91.73 & \\
\hline se & 49.20 & & 123.95 & & 44.89 & & 184.10 & & 444.34 & & 146.76 & \\
\hline Other External & -4.03 & & -20.91 & & -2.49 & & 25.48 & & -9.56 & & 14.80 & \\
\hline \multirow[t]{2}{*}{ se } & 9.37 & & 20.75 & & 10.66 & & 42.12 & & 85.25 & & 40.78 & \\
\hline & \multicolumn{12}{|c|}{ Women } \\
\hline Cause of Death & All Education & & >High Sch & & $<=$ High Sch & & All Education & & >High Sch & & $<=$ High Sch & \\
\hline All Causes & -265.40 & & -365.82 & & -291.27 & $*$ & 143.26 & & 1470.36 & & -75.77 & \\
\hline std. error & 136.52 & & 319.60 & & 116.40 & & 450.81 & & 1134.55 & & 320.98 & \\
\hline DoD & 2.21 & & -.98 & & 31.67 & $* *$ & 31.94 & $*$ & 30.74 & & 35.20 & $*$ \\
\hline se & 9.26 & & 18.09 & & 10.67 & & 14.07 & & 29.42 & & 15.27 & \\
\hline Cancer & -82.67 & & -60.05 & & -139.89 & $* *$ & -26.36 & & 592.80 & & -116.84 & \\
\hline se & 71.88 & & 198.58 & & 52.06 & & 157.58 & & 526.70 & & 94.84 & \\
\hline CVD & -26.36 & & -76.99 & & -41.37 & & 172.48 & & 499.26 & & 81.60 & \\
\hline se & 35.56 & & 66.59 & & 33.53 & & 169.19 & & 362.91 & & 124.90 & \\
\hline Other Internal & -150.32 & $* *$ & -217.68 & $* *$ & -133.87 & $* *$ & -46.10 & & 231.15 & & -86.31 & \\
\hline se & 29.60 & & 52.50 & & 32.36 & & 113.45 & & 235.98 & & 97.89 & \\
\hline Other External & -7.76 & $*$ & -7.07 & & -7.82 & $*$ & 11.76 & & 130.67 & & 10.26 & \\
\hline se & 3.56 & & 9.15 & & 3.90 & & 9.76 & & 101.32 & & 9.73 & \\
\hline
\end{tabular}

Source: Authors' tabulations using 1990 to 2014 National Vital Statistics, U.S. decennial census, and American Community Survey.

Notes: ${ }^{*} * \mathrm{P}<0.01 ; * \mathrm{P}<0.05 ; \mathrm{DoD}=$ Deaths of Despair; $\mathrm{CVD}=\mathrm{Cardiovascular}$ disease; se $=$ (robust) standard error 
Table 4. Coefficient estimates in regressions of ASDR change on shift-share employment instrument, ages 45 to 54

\begin{tabular}{|c|c|c|c|c|c|c|c|c|c|c|c|}
\hline \multirow[b]{3}{*}{ Cause of Death } & \multicolumn{5}{|c|}{ non-Hispanic Whites } & \multicolumn{6}{|c|}{ non-Hispanic Blacks } \\
\hline & \multicolumn{11}{|c|}{ Men } \\
\hline & All Education & & $>$ High Sch & & $<=$ High Sch & & All Education & & $>$ High Sch & $<=$ High Sch & \\
\hline All Causes & -254.28 & & -484.10 & & -333.37 & $*$ & 332.90 & & 407.26 & 136.29 & \\
\hline std. error & 133.65 & & 317.34 & & 135.43 & & 537.95 & & 1070.43 & 409.18 & \\
\hline DoD & -14.28 & & -25.06 & & 19.93 & & 97.76 & $*$ & 56.36 & 107.07 & $* *$ \\
\hline se & 16.74 & & 26.45 & & 19.69 & & 40.93 & & 59.56 & 38.81 & \\
\hline Cancer & -55.85 & & -96.32 & & -119.86 & $* *$ & 49.97 & & 271.77 & -68.14 & \\
\hline se & 38.63 & & 96.42 & & 39.14 & & 136.22 & & 279.94 & 101.37 & \\
\hline CVD & .44 & & -49.44 & & -69.21 & & 220.38 & & 212.84 & 124.48 & \\
\hline se & 45.32 & & 94.04 & & 51.12 & & 178.33 & & 315.22 & 141.96 & \\
\hline Other Internal & -171.07 & $* *$ & -282.85 & $*$ & -146.43 & $* *$ & -82.08 & & -77.91 & -72.27 & \\
\hline se & 41.17 & & 117.63 & & 34.73 & & 156.78 & & 399.89 & 120.67 & \\
\hline Other External & -13.33 & & -29.20 & & -17.86 & & 47.68 & & -51.24 & 44.86 & \\
\hline \multirow[t]{2}{*}{ se } & 9.36 & & 19.85 & & 12.61 & & 45.68 & & 92.84 & 45.68 & \\
\hline & \multicolumn{11}{|c|}{ Women } \\
\hline Cause of Death & All Education & & $>$ High Sch & & $<=$ High Sch & & All Education & & >High Sch & $<=$ High Sch & \\
\hline All Causes & -245.25 & $* *$ & -261.13 & & -290.48 & $* *$ & 30.07 & & 320.66 & -179.18 & \\
\hline std. error & 74.36 & & 164.58 & & 78.56 & & 287.62 & & 679.87 & 229.54 & \\
\hline DoD & -13.37 & & -12.92 & & 15.19 & & 27.69 & & 31.48 & 23.61 & \\
\hline se & 11.44 & & 23.17 & & 13.08 & & 16.55 & & 34.41 & 18.58 & \\
\hline Cancer & -50.02 & & -25.46 & & -100.57 & $* *$ & -5.51 & & 317.65 & -92.48 & \\
\hline se & 40.71 & & 107.20 & & 35.61 & & 104.69 & & 310.00 & 75.49 & \\
\hline CVD & -54.74 & $* *$ & -72.05 & $* *$ & -73.22 & $* *$ & 34.79 & & 38.42 & -33.64 & \\
\hline se & 16.27 & & 27.74 & & 20.33 & & 93.60 & & 209.50 & 76.26 & \\
\hline Other Internal & -113.76 & $* *$ & -136.87 & $* *$ & -117.92 & $* *$ & -43.13 & & -33.08 & -93.41 & \\
\hline se & 17.33 & & 28.18 & & 22.66 & & 80.08 & & 152.25 & 76.74 & \\
\hline Other External & -12.99 & $* *$ & -11.86 & & -13.96 & $*$ & 16.21 & & -31.62 & 16.53 & \\
\hline se & 4.03 & & 9.17 & & 5.60 & & 10.75 & & 35.53 & 12.45 & \\
\hline
\end{tabular}

Source: Authors' tabulations using 1990 to 2014 National Vital Statistics, U.S. decennial census, and American Community Survey.

Notes: $* * \mathrm{P}<0.01 ; * \mathrm{P}<0.05 ; \mathrm{DoD}=$ Deaths of Despair; $\mathrm{CVD}=$ Cardiovascular disease; $\mathrm{se}=($ robust $)$ standard error 
Figure 1. Mean Actual and Predicted Changes in Age-Standardized Death Rates,

non-Hispanic, White Men, 45 to 64, Low Education

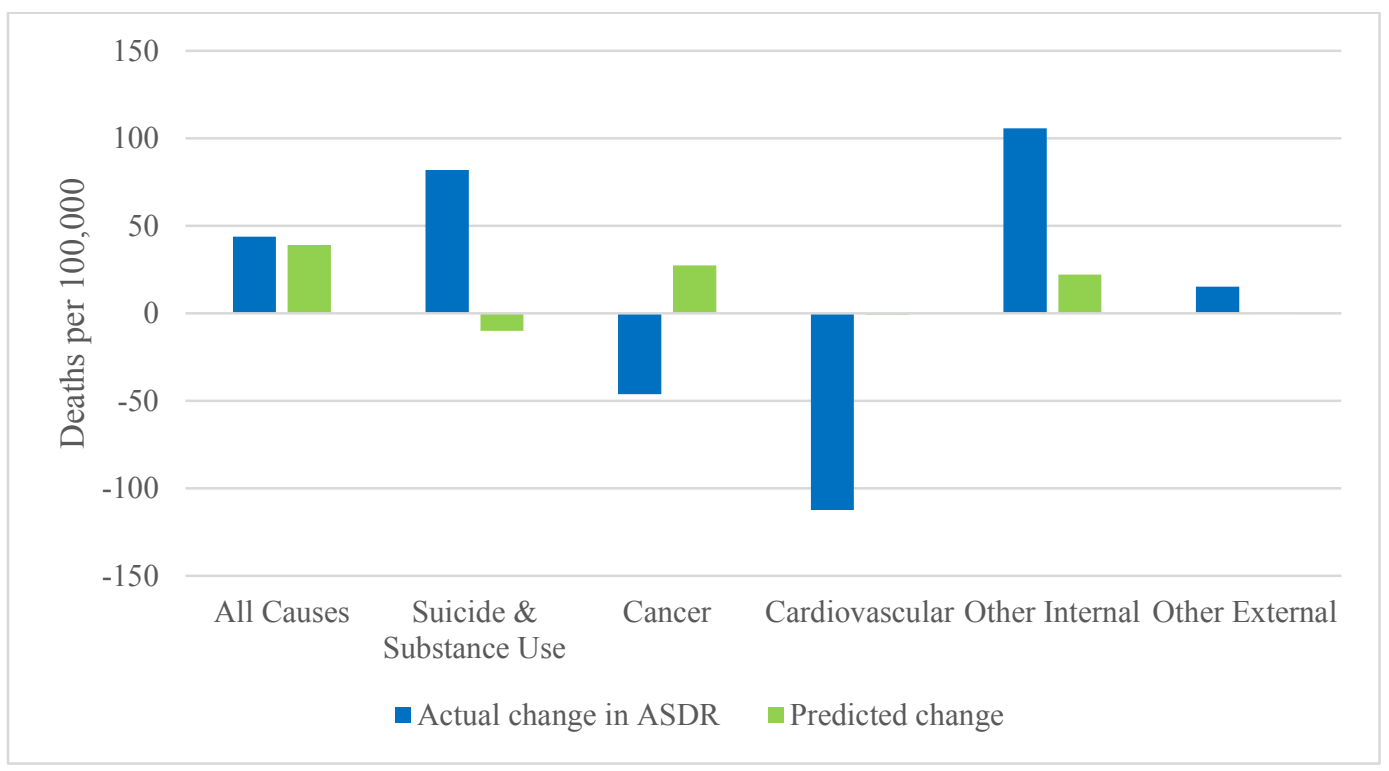

Source: Authors' tabulations using 1990 to 2014 National Vital Statistics, U.S. decennial census, and American Community Survey. 
Figure 2. Mean Actual and Predicted Changes in Age-Standardized Death Rates, non-Hispanic, White Women, 45 to 64, Low Education

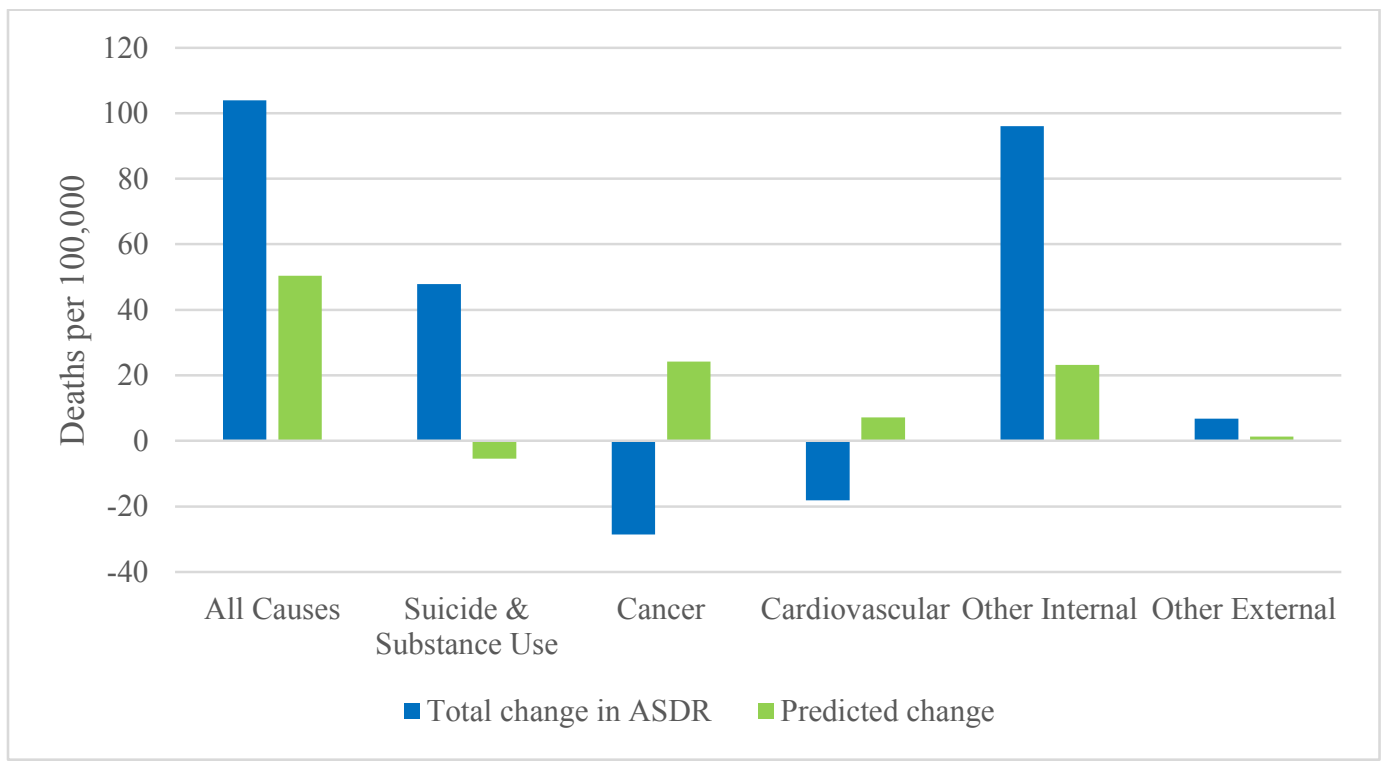

Source: Authors' tabulations using 1990 to 2014 National Vital Statistics, U.S. decennial census, and American Community Survey. 